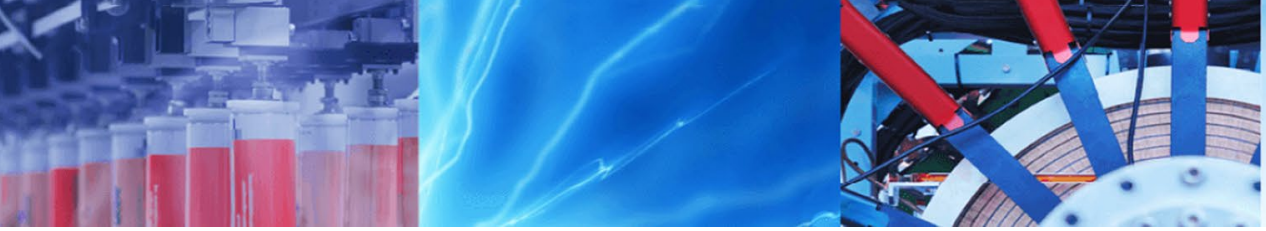

Research Article

\title{
The role of precursor decomposition in the formation of samarium doped ceria nanoparticles via solid-state microwave synthesis
}

\author{
Avi Bregman ${ }^{1} \cdot$ Jessica Rimsza ${ }^{2}$ Marissa Ringgold ${ }^{1}$. Nelson Bell ${ }^{1} \cdot$ LaRico Treadwell $^{1,2}$ (D)
}

Received: 17 November 2020 / Accepted: 27 January 2021 / Published online: 17 February 2021

(C) The Author(s) 2021 OPEN

\begin{abstract}
The impact on the final morphology of ceria $\left(\mathrm{CeO}_{2}\right)$ nanoparticles made from different precursors (commercial: cerium acetate/nitrate) and in house: cerium tri(methylsilyl)amide (Ce-TMSA)) via a microwave solid state reaction has been determined. In all instances, powder X-ray diffraction indicated that the cubic fluorite $\mathrm{CeO}_{2}$ phase (PDF\# 04-004-9150, with the space group Fm-3 m) had formed. Scanning electron microscopy (SEM) images revealed spherical nanoparticles were produced from the Ce-TMSA precursor. The commercial acetate and nitrate precursors produced particles with irregular morphology. The roles of the precursor decomposition and binding energy in the synthesis of the nanocrystals with various morphologies, as well as a possible growth mechanism, were evaluated based on experimental and computational data. The formation of spherical shaped nanoparticles was determined to be due to the preferential single-step decomposition of the Ce-TMSA as well as the low activation energy to overcome decomposition. Due to the complicated decomposition of the commercial precursors and high activation energy the resulting particles adopted an irregular morphology. Highly uniform samarium doped ceria $\left(\mathrm{Sm}_{\mathrm{x}} \mathrm{Ce}_{1-\mathrm{x}} \mathrm{O}_{2-\delta}\right)$ nanospheres were also synthesized from Ce-TMSA and samarium tri(methylsilyl)amide (Sm-TMSA). The effects of reaction time and temperature, on the final morphology were observed through SEM. The rapid single-step decomposition of TMSA-based precursors as observed through thermogravimetric analysis (TGA) and confirmed through the calculation of potential energy surfaces and binding energies from density functional theory (DFT) calculations, indicated that nanoparticle formation follows LaMer's classical nucleation theory.
\end{abstract}

Keywords Solid-state $\cdot$ Microwave $\cdot$ Solvent-free $\cdot$ Doped cerium oxide

\section{Introduction}

Ceria $\left(\mathrm{CeO}_{2}\right)$ nanomaterials have found widespread use in sensors [1, 2], absorbers, [3] and fuel cells as a solid electrolyte due to their inherent physical properties including, chemical inertness, ionic conductivity, high dielectric constant, and moderate band gap [4,5]. The size of the $\mathrm{Ce}^{4+}$ cation $(0.96 \AA)$ and its inherent crystal structure allows for easy doping of $\mathrm{CeO}_{2}$ by trivalent lanthanide cations $\left(\mathrm{Ln}^{3+}\right)$; the open structure of the cubic fluorite lattice can accommodate high levels of point defect disorder [6]. This property has led to the development of easily doped $\mathrm{CeO}_{2}$ materials like $\mathrm{Sm}_{\mathrm{x}} \mathrm{Ce}_{1-\mathrm{x}} \mathrm{O}_{2-\delta}$ and $\mathrm{Gd}_{\mathrm{x}} \mathrm{Ce}_{-\mathrm{x}} \mathrm{O}_{2-\delta}$. Doping $\mathrm{CeO}_{2}$ with $\mathrm{Ln}^{3+}$ cations introduces significant oxygen vacancies which can increase ionic conductivity over neat $\mathrm{CeO}_{2}$. There have been many reports on the synthesis of doped $\mathrm{CeO}_{2}$ materials [7-11], but among these new materials, samarium doped ceria $\left(\mathrm{Sm}_{\mathrm{x}} \mathrm{Ce}_{1-\mathrm{x}} \mathrm{O}_{2-\delta}\right)$ has emerged as one of the more promising doped $\mathrm{CeO}_{2}$ materials due to the similarities in ionic radii of $\mathrm{Ce}^{4+}(0.96 \AA)$ and $\mathrm{Sm}^{3+}$

Supplementary Information The online version of this article (https://doi.org/10.1007/s42452-021-04288-y).

LaRico Treadwell, ljtread@sandia.gov| 'Sandia National Laboratories, Advanced Materials Lab, Albuquerque, NM 87108, USA. ${ }^{2}$ Geochemistry Department, Sandia National Laboratories, Albuquerque, NM 87108, USA. 
$(1.09 \AA)$; this allows for easy solid solution formation. Upon successful doping, $\mathrm{Sm}_{x} \mathrm{Ce}_{1-x} \mathrm{O}_{2-\delta}$ has reported one of the higher ionic conductivities and particularly low operating temperature requirements [12]. For example, Huang et al. showed a nearly two order of magnitude increase in ionic conductivity at $600{ }^{\circ} \mathrm{C}$ by doping $\mathrm{CeO}_{2}$ with $23 \%$ samarium [13].

It has been reported that the properties of $\mathrm{CeO}_{2}$-based ceramics are highly dependent on the size, shape, and crystalline phase of the particles [14-16]. For instance, Mai et al. observed an oxygen storage content of $554 \mu \mathrm{mol} O$ $\mathrm{g}^{-1}$ for $\mathrm{CeO}_{2}$ nanorods compared to an oxygen storage content of $318 \mu \mathrm{mol} \mathrm{O} \mathrm{g}{ }^{-1}$ for $\mathrm{CeO}_{2}$ nanopolyhedra [16]. Ma et al. utilized a novel hydrothermal method to synthesize $\mathrm{Sm}_{\mathrm{x}} \mathrm{Ce}_{1-\mathrm{x}} \mathrm{O}_{2-\delta}$ nanorods, which due to their increased surface area, displayed a very high power density of 522 $\mathrm{mW} \mathrm{cm}{ }^{-2}$ [17]. Since the shape-phase-property relationship is important for various applications, it is critical to establish control over the morphology of $\mathrm{CeO}_{2}$ based materials (i.e., morphology, phase, shape, etc.) as a function of $\mathrm{Ln}^{3+}$ doping. Previous efforts to tailor the morphology of various $\mathrm{CeO}_{2}$-based nanoparticles have been investigated using commercially available precursors by altering specific synthesis variables, such as $\mathrm{pH}$ [18], precursors [19], and surfactants [20]. Recently, Wang et al. demonstrated the synthesis of $\mathrm{CeO}_{2}$ in the form of stacked nanoplatelets, nanorods, nanosquares, and round nanoplatelets using a solution-based synthesis in the presence of different mineralizers [21]. While morphological control of neat $\mathrm{CeO}_{2}$ and trivalent doped $\mathrm{CeO}_{2}$ has been realized by varying the $\mathrm{pH}$, surfactant, and precursors in solution, to the best of our knowledge there has been no report on the systematic comparison of nonvolatile (commercial/ hydrate/air-stable) vs volatile (in-house/non-hydrate/ air-unstable) precursors for the production of neat and $\mathrm{Ln}^{3+}$-doped $\mathrm{CeO}_{2}$ nanoparticles.

A broad variety of synthesis processes has been utilized to make $\mathrm{CeO}_{2}$-based nanomaterials including: hydrothermal methods [22], solvothermal methods [23], co-precipitation [24], sol-gel [23], and microemulsion [25]. While many of these methods have produced high quality materials with good shape and size control, they are reliant on secondary mechanisms/catalysts such as surfactants and $\mathrm{pH}$. Furthermore, they can involve aging steps or complex surfactant washing procedures that make them unattractive for large scale synthesis. As an alternative to solutionbased techniques, solid-state reactions have the potential for direct preparation of economically viable, high-purity, stoichiometric metal oxide nanoparticles while avoiding many of the aforementioned complexities [26]. Solidstate reactions can also be improved upon by utilizing microwave heating. Compared to conventional heating methods, microwave heating is more efficient, has a more homogenous heating profile, and can lead to higher yields [27].

Given the limited investigations of traditional vs nontraditional precursors to produce faceted nanoparticles, a systematic approach was taken to produce $\mathrm{CeO}_{2}$ and $\mathrm{Sm}_{x} \mathrm{Ce}_{1-\mathrm{x}} \mathrm{O}_{2-\delta}$ nanoparticles by decomposing traditional cerium/samarium acetate hydrate (Ln-acetate) and cerium/samarium nitrate hexahydrate (Ln-nitrate) precursors, as well as nontraditional samarium/cerium tri(methylsilyl)amide (Ln-TMSA) precursors via microwaveassisted solid state in ambient conditions. This report details the synthesis, characterization, and growth mechanism of $\mathrm{CeO}_{2}$ and $\mathrm{Sm}_{\mathrm{x}} \mathrm{Ce}_{1-\mathrm{x}} \mathrm{O}_{2-\delta}$ nanoparticles. The effect of different precursors to produce $\mathrm{Sm}_{\mathrm{x}} \mathrm{Ce}_{1-\mathrm{x}} \mathrm{O}_{2-\delta}$ nanoparticles as well as the effects of reaction temperature, time, and initial molar ratio were investigated. Details of the possible growth mechanism of spherical nanoparticle of $\mathrm{CeO}_{2}$ and $\mathrm{Sm}_{\mathrm{x}} \mathrm{Ce}_{1-\mathrm{x}} \mathrm{O}_{2-\delta}$ nanoparticles are explained through thermogravimetric analysis (TGA) and density functional theory (DFT) calculations that reinforce the classic LaMer growth mechanism.

\section{Experimental}

\subsection{Materials and methods}

All syntheses were performed under-atmospheric conditions, unless otherwise stated. Cerium(III) nitrate hexahydrate, samarium(III) nitrate hexahydrate, cerium(III) acetate hydrate and samarium(III) acetate hydrate, cerium(III) chloride, samarium(III) chloride, and potassium bis(trimethylsilyl)amide $\left(\mathrm{KNR}_{2}\right)$, toluene, tetrahydrofuran (THF) and hexanes, were purchased from Sigma-Aldrich, USA. Cerium(III) TMS and samarium(III) TMS were prepared in-house using established literature routes [28]. All reagents were of analytical grade and used without further purification.

\subsection{Characterization methods}

Analytical data were collected on dry, free-flowing powders. Powder X-ray diffraction (PXRD) of the products were conducted on a zero-background holder by a Siemens D500 Diffractometer equipped with a graphite monochromator with Cu Ka radiation operating at $45 \mathrm{kV}$ and $40 \mathrm{~mA}$. The samples were scanned at a rate of $4 \%$ in the $2 \theta$ range of $20^{\circ}-100^{\circ}$. The patterns were analyzed with the JADE 9.6.0 software with ICDD PDF-4 database. Raman spectra were obtained using a Witec Raman Confocal Microscope with an excitation laser operating at $532 \mathrm{~nm}$. X-ray fluorescence (XRF) spectra were obtained using a Thermo Scientific ARL Quant'X EDXRF Analyzer. For all scanning electron 
microscopy (SEM) analyses, the samples were dispersed on carbon tape and examined with a Hitachi S-5200 Scanning Electron Microscope under an accelerating voltage of $5 \mathrm{kV}$ and a current of 7A. Differential scanning calorimetry (DSC) and TGA were measured using a Mettler Toledo TGA/ DSC 3 + Thermogravimetric Analyzer equipped with a high temperature $(\mathrm{HT})$ furnace. The samples were heated a rate of $5^{\circ} \mathrm{C} / \mathrm{min}$ in the temperature range of $25-500^{\circ} \mathrm{C}$.

\subsection{Computational Details}

To complement experimental TGA analysis, gas-phase electronic structure calculations were performed for $\mathrm{Ln}$ TMSA and Ln-acetate (representative of the commercial precursors) using Gaussian 09 [29] at the DFT level with the hybrid B3LYP functional (Becke's three parameter hybrid exchange functional with Lee-Yang-Parr correlation function) [30-32]. The small-core effective core potential (ECP) MWB28 was used for the $\mathrm{Ce}$ and Sm atoms [33]. All other atoms were described using the $6-31 \mathrm{G}$ basis set $[32,34$, 35] as part of the complete basis set model described by Petersson et al. [36]. The ECP MWB28 core potentials include a scalar relativistic correction and has been previously applied to $\mathrm{Ce}$ - and $\mathrm{Sm}$-based molecules resulting in agreement with experimental structures [37, 38]. Molecular structures were selected from solved crystal structures and optimized in unrestricted calculations. All atoms were allowed to relax during optimization. Agreement in the metrical data between the crystal structures and DFT optimized molecules (Table S1) validates the quality of the DFT models and is discussed in the results. Potential energy surface (PES) scans were performed to identify the strength of the Ln-TMSA interaction and the presence of intermediate states during disassociation. The $\mathrm{Ln}-\mathrm{N}$ distance was stretched by $0.05 \AA$, and then the structure was relaxed. No other constraints were placed on the system during relaxation. This process was repeated iteratively until the Ln-N distance reached $5.0 \AA$. In addition to the PES scans, dissociation energy $\left(E_{D}\right)$ data was collected for complete removal of the trimethylsilyl amide (TMSA) ligand. $E_{D}$ data was calculated by removing a TMSA ligand from the Ln-TMSA molecule and relaxing the resulting structure as well as the lone TMSA ligand. $E_{D}$ was calculated as the difference between the molecule $\left(E_{L n-T M S A}\right)$, the energy of a lone TMSA ligand $\left(E_{T M S A}\right)$, and the energy of the precursor without a third TMSA ligand ( $\left.E_{\text {Ln-TMSA-TMSA }}\right)$ :
$E_{D}=\left(E_{L n-T M S A-T M S A}+E_{T M S A}\right)-E_{L n-T M S A}$

\subsection{Preparation of Ln-TMSA precursors}

Separate solutions of $\mathrm{LnCl}_{3}$ in $\mathrm{THF}$ and $\mathrm{KNR}_{2}$ in $\mathrm{THF}$ were prepared in inert atmosphere. The $\mathrm{LnCl}_{3}$ solution was cooled and progressively treated with the $\mathrm{KNR}_{2}$ solution. The final mixture was stirred overnight, filtered with hexanes, extracted with toluene, and then stripped again to yield Ln-TMSA powder.

\subsection{Microwave-assisted solid-state synthesis of $\mathrm{Sm}_{x} \mathrm{Ce}_{1-\mathrm{x}} \mathrm{O}_{2-\delta}$ powders}

$\mathrm{CeO}_{2}$ and $\mathrm{Sm}_{\mathrm{x}} \mathrm{Ce}_{1-\mathrm{x}} \mathrm{O}_{2-\delta}$ nanoparticles were prepared via solid state microwave radiation of the respective metal precursors (Ln-nitrate, Ln-acetate, Ln-TMSA) in the presence of atmospheric air. All reactions involving acetate and nitrate precursors were prepared and performed in ambient conditions, while the Ln-TMSA precursors were handled in a glove box prior to heating in ambient conditions. In a standard synthesis method, the precursor was ground in a mortar to insure a homogenous mixture. After mixing the necessary precursors, the reaction was heated in a Microwave Research and Application BP-210 microwave oven under atmospheric conditions at $750^{\circ} \mathrm{C}$, using air as the reaction media. For the formation of $\mathrm{Sm}_{x} \mathrm{Ce}_{1-x} \mathrm{O}_{2-\delta}$ various ratios and reaction conditions of Ce-TMSA and Sm-TMSA, shown in Table 1, were attempted to increase the $\mathrm{Sm}^{3+}$ dopant concentration and control the physical nature of the material (size, morphology, and crystallinity). After the reactions were conducted as described the isolated materials were collected and analyzed without further modifications.

\section{Results and discussion}

The robust and diverse physical properties of $\mathrm{CeO}_{2}$ and $\mathrm{Sm}_{\mathrm{x}} \mathrm{Ce}_{1-\mathrm{x}} \mathrm{O}_{2-\delta}$ have led to numerous investigations detailing the morphological impact on their optical and electronic properties [39, 40]; however, there are no reports on understanding the generation of the aforementioned materials using traditional vs non-traditional precursors in a microwave without the presence of a liquid solution
Table 1 SmxCe1-xO2- $\delta$ Reaction Conditions

\begin{tabular}{lllllllll}
\hline Reaction Condition & A & B & C & D & E & F & G & $H$ \\
\hline Ce:Sm Ratio & $1: 0$ & $4: 1$ & $4: 1$ & $4: 1$ & $3: 1$ & $2: 1$ & $2: 1$ & $2: 1$ \\
Dwell Temperature $\left({ }^{\circ} \mathrm{C}\right)$ & 750 & 1000 & 750 & 500 & 750 & 750 & 750 & 750 \\
Dwell Time $(\mathrm{min})$ & 10 & 10 & 10 & 10 & 10 & 10 & 5 & 20 \\
\hline
\end{tabular}


or surfactant. Due to the shape-dependent properties of nanomaterials and the void in literature on microwaveassisted solid-state synthesis of various precursors, it was of interest to investigate the effect of traditional and nontraditional precursors, on the properties of the resultant $\mathrm{CeO}_{2}$ and $\mathrm{Sm}_{\mathrm{x}} \mathrm{Ce}_{1-\mathrm{x}} \mathrm{O}_{2-\delta}$ nanoparticles. Therefore, a systematic study was undertaken, and the results discussed below focus on the crystal structure and particle morphology of resulting nanoparticles. A growth mechanism is also described based on the (i) decomposition profiles, (ii) calculated dissociation energies, and (iii) calculated potential surfaces of precursor materials.

\subsection{Formation of spherical cerium oxide nanoparticles}

PXRD data, shown in Fig. 1a, was collected on the powders isolated from reacting the Ce-precursors (acetate, nitrate, and TMSA) at $750^{\circ} \mathrm{C}$ for $10 \mathrm{~min}$. For each sample the major peaks of the PXRD patterns were indexed to the cubic fluorite $\mathrm{CeO}_{2}$ phase (PDF\# 04-004-9150) with the space group Fm-3 $\mathrm{m}$ and no other impurities can be observed in the patterns. SEM images of products generated from the microwave reaction of the individual $\mathrm{Ce}$-precursors are shown in Fig. 1b-d. Figure 1b, c show SEM images of the product formed from $\mathrm{Ce}$-acetate and $\mathrm{Ce}$-nitrate, respectively. For these systems, highly irregular $\mathrm{CeO}_{2}$ nanoparticles are present as well as agglomerated particles. The irregular morphology of the acetate and nitrate-based $\mathrm{CeO}_{2}$ indicates that there are adsorbed surface species during the conversion reaction, and that transport of ions on the surfaces is not rapid enough to form regular facets based on crystal symmetry. However, Fig. 1d shows that decomposition of the Ce-TMSA precursor yields $\mathrm{CeO}_{2}$ nanoparticles with a highly defined spherical morphology. In contrast, Ce-TMSA processed in a conventional furnace with identical conditions yielded a minute amount of spherical nanoparticles with the majority exhibiting
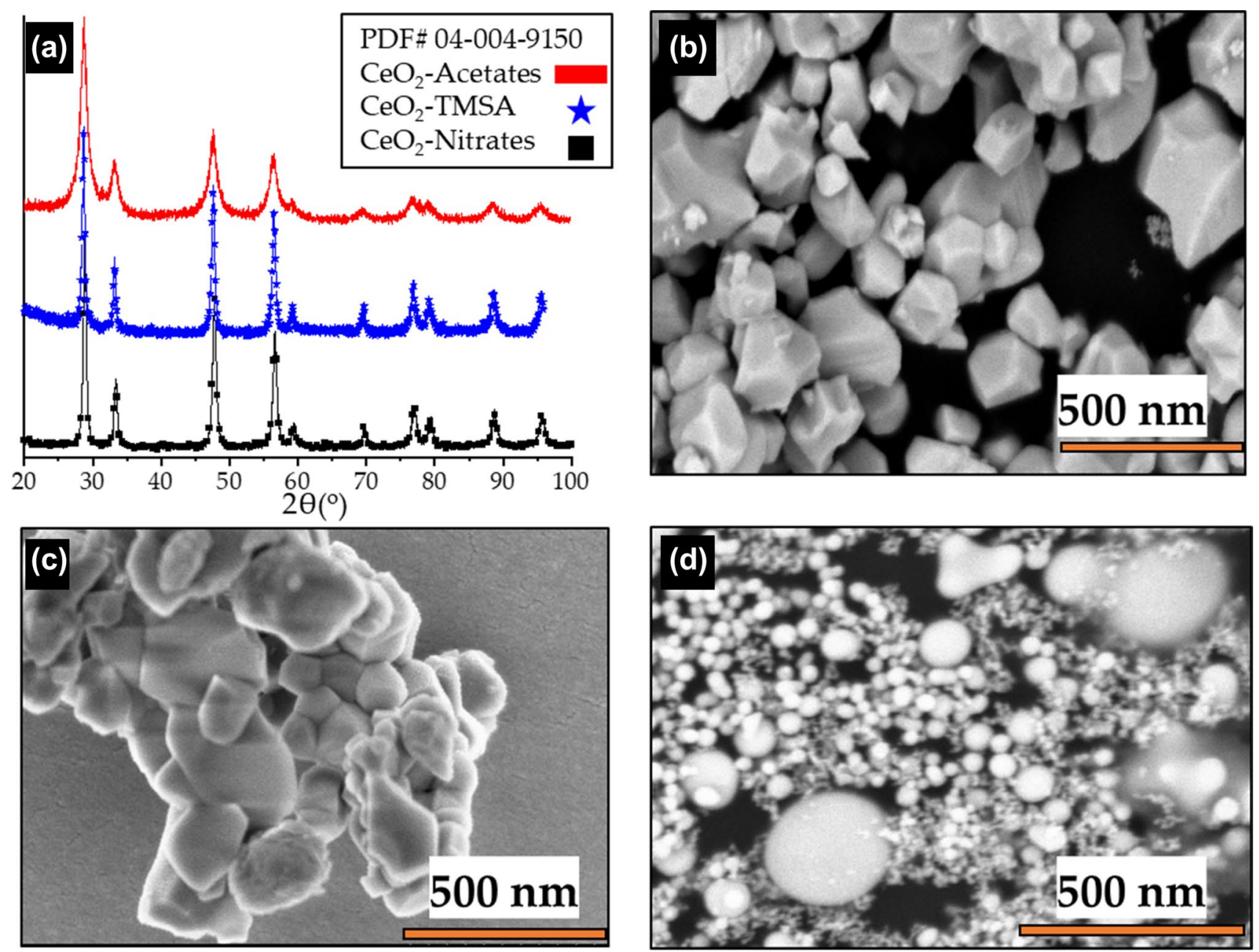

Fig. 1 PXRD spectra a confirms that all precursors lead to highly crystalline cerium oxide. SEM images of nanoparticles synthesized from $\mathbf{b}$ Ce-acetate $\mathbf{c}$ Ce-nitrate and $\mathbf{d}$ Ce-TMSA precursors synthesized at a reaction temp of $750{ }^{\circ} \mathrm{C}$ and a reaction time of $10 \mathrm{~min}$ 
irregular morphology, as shown in Figure S1. The round spherical morphology agrees with a rapid decomposition process achieved through rapid microwave heating, where cation transport to the nuclei is diffusion limited. These variations in growth kinetics and nucleation will be discussed more in depth in the growth mechanism section.

\subsection{Formation of Samarium-Doped Ceria Nanospheres}

Due to the serendipitous generation of spherical $\mathrm{CeO}_{2}$ nanoparticle from microwave irradiation of the Ce-TMSA precursor, $\mathrm{Sm}_{\mathrm{x}} \mathrm{Ce}_{1-\mathrm{x}} \mathrm{O}_{2-\delta}$ was synthesized by combining $\mathrm{Ce}-$ TMSA and Sm-TMSA precursors. $\mathrm{Sm}_{\mathrm{x}} \mathrm{Ce}_{1-\mathrm{x}} \mathrm{O}_{2-\delta}$ was generated with an initial Ce:Sm molar ratio of 4:1,3:1, 2:1 and a reaction time of $10 \mathrm{~min}$ at $1000^{\circ} \mathrm{C}$. PXRD data, shown in Fig. 2a, were collected on the powders isolated from the different reaction conditions. The crystalline product was indexed to the cubic fluorite phase (PDF\# 04-0049150), with no secondary phase present $\left(\mathrm{Sm}_{2} \mathrm{O}_{3}\right.$; cubic la-3 phase). Upon addition of $\mathrm{Sm}^{3+}$, the PXRD patterns exhibit a Sm${ }^{3+}$ concentration-dependent downfield shift relative to $\mathrm{CeO}_{2}$ for all the major reflections, which can be seen clearly in Fig. 2b. The shift to lower angles is due to lattice strain from size mismatch cause by the uptake of differently sized $\mathrm{Sm}^{3+}$ ions, suggesting the successful incorporation of $\mathrm{Sm}^{3+}$ in the cubie lattice of $\mathrm{CeO}_{2}$ [41]. As shown in Fig. $2 \mathrm{c}$, production of $\mathrm{Sm}_{\mathrm{x}} \mathrm{Ce}_{1-\mathrm{x}} \mathrm{O}_{2-\delta}$ yielded spherical nanoparticles, indicating that uptake of $\mathrm{Sm}^{3+}$ ions does not affect the final morphology.

In order to confirm the uptake of $\mathrm{Sm}^{3+}$ ions in the cubic fluorite $\mathrm{CeO}_{2}$ lattice as well as to ascertain any structural changes, $\mathrm{Sm}_{x} \mathrm{Ce}_{1-\mathrm{x}} \mathrm{O}_{2-\delta}$ powders were analyzed via Raman spectroscopy and XRF (Figure S2). Representative Raman spectra for as synthesized $\mathrm{CeO}_{2}$ and $\mathrm{Sm}_{\mathrm{x}} \mathrm{Ce}_{1-\mathrm{x}} \mathrm{O}_{2-\delta}$ are shown in Fig. 3. The major peak for both powders is the triply degenerate $F_{2 g}$ band at $\sim 460 \mathrm{~cm}^{-1}$ which is assigned to the $\mathrm{CeO}_{2}$ cubic fluorite structure [42]. This Raman active mode is attributed to the symmetric breathing of oxygen around the central cerium ions [43]. The symmetry of this breathing mode means that they are sensitive to disorder in the oxygen lattice that can occur through doping. Upon $\mathrm{Sm}^{3+}$ incorporation in $\mathrm{CeO}_{2}$, a broad absorption band in the region of $520-630 \mathrm{~cm}^{-1}$ emerges as oxygen vacancies are introduced and disorder is introduced into the oxygen sublattice. Additionally, the $F_{2 g}$ peak becomes asymmetric, broadens, and shifts to lower frequencies due to increased oxygen vacancy and changes in the lattice structure [44]. This result is consistent with other reports of $\mathrm{Sm}_{x} \mathrm{Ce}_{1-x} \mathrm{O}_{2-\delta}$ $[45,46]$.

\subsection{Effect of synthesis parameters on nanoparticles size}

To understand the effect of temperature on the formation of $\mathrm{Sm}_{\mathrm{x}} \mathrm{Ce}_{1-\mathrm{x}} \mathrm{O}_{2-\delta}$, Ln-TMSA based nanoparticles with
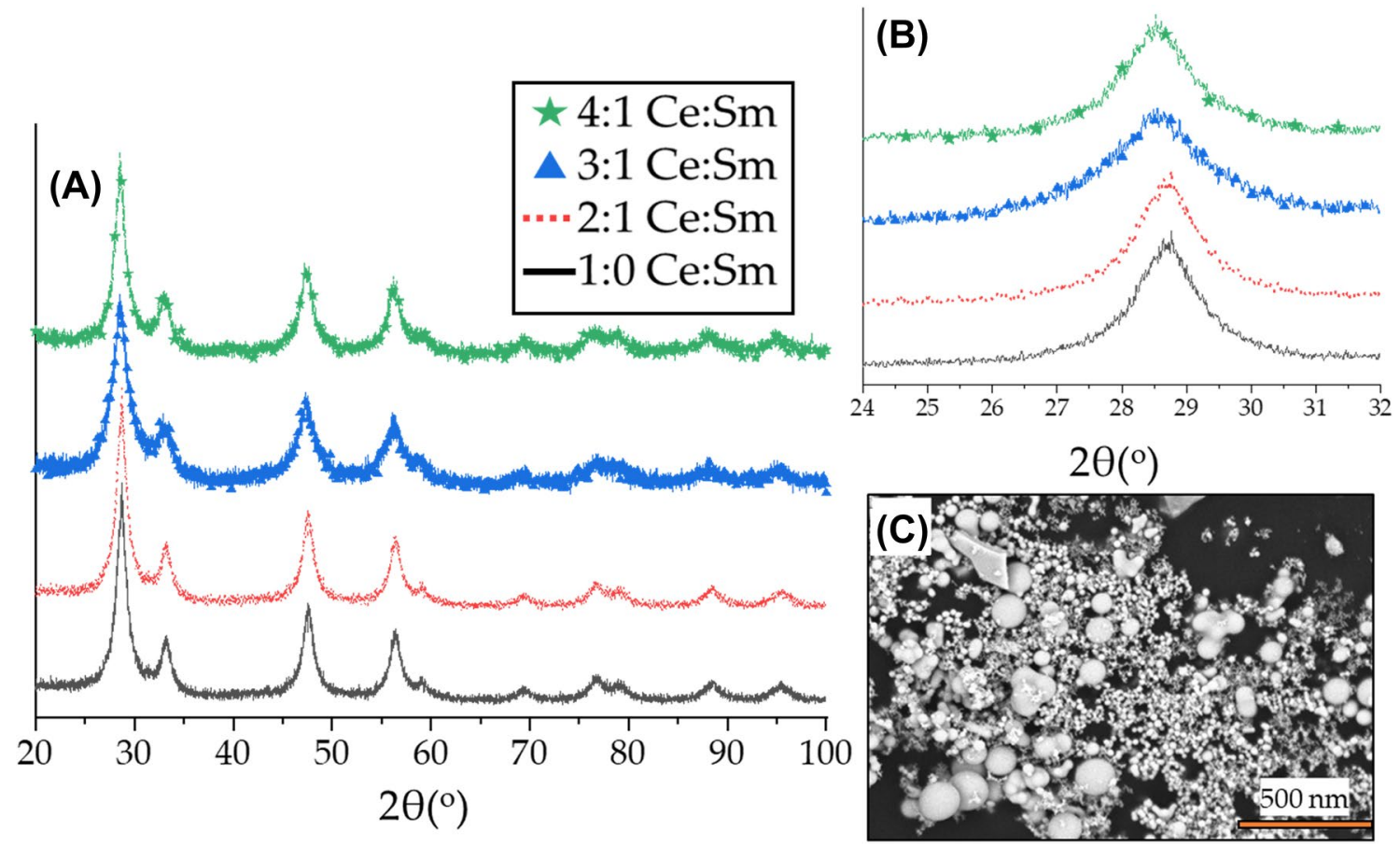

Fig. 2 a PXRD spectra of $\mathrm{Sm}_{\mathrm{x}} \mathrm{Ce}_{1-\mathrm{x}} \mathrm{O}_{2-\delta}$ prepared with variable starting Ce:Sm ratios. The PXRD inset in $\mathbf{b}$ shows the downfield shift in the spectra of $\mathrm{CeO}_{2}$ upon the addition of samarium ions. c SEM images of $\mathrm{Sm}_{x} \mathrm{Ce}_{1-x} \mathrm{O}_{2-\delta}$ nanoparticles shows spherical morphology 


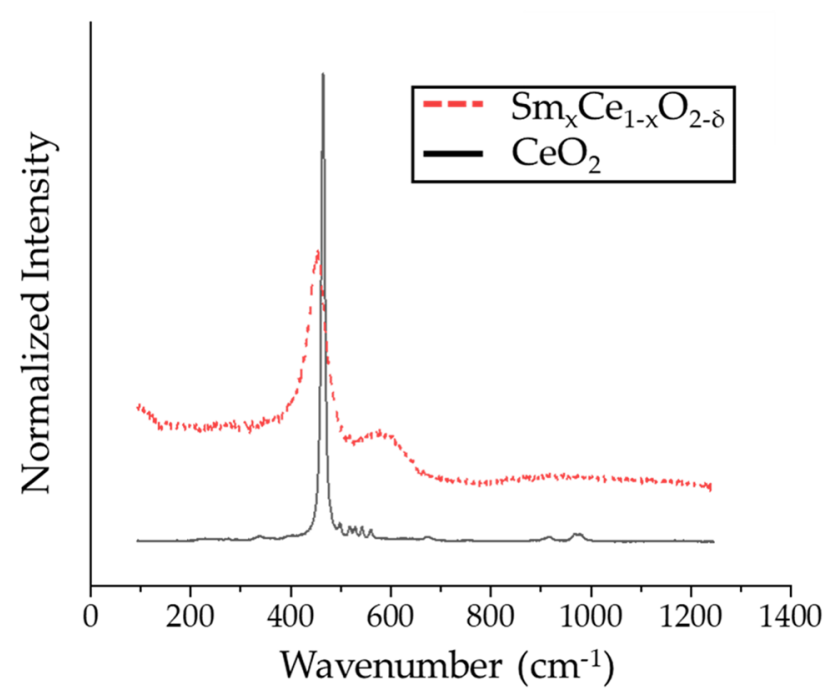

Fig. 3 Raman spectra of $\mathrm{CeO}_{2}$ and $\mathrm{Sm}_{\mathrm{x}} \mathrm{Ce}_{1-\mathrm{x}} \mathrm{O}_{2-\delta}$

an initial Ce:Sm ratio of $4: 1$ of were investigated at $500^{\circ} \mathrm{C}$, $750^{\circ} \mathrm{C}$, and $1000^{\circ} \mathrm{C}$ for $10 \mathrm{~min}$, respectively. SEM images of the product from this study are shown in Fig. 4a-c. At all temperatures spherical nanoparticles were obtained, however, there is variation in final nanoparticle size. To quantify the effect of temperature on the size dispersion of the product, the diameter of $>200$ particles were analyzed and plotted in histograms for each reaction, shown in Fig. 4d-f. At a final processing temperature of $500^{\circ} \mathrm{C}$ the majority of the nanoparticles have diameters between $10-50 \mathrm{~nm}$, at $750^{\circ} \mathrm{C}$ the average diameter increases to $75-125 \mathrm{~nm}$, and at $1000^{\circ} \mathrm{C}$ most particles have diameters between $175-250 \mathrm{~nm}$. It is worth noting that the particle distributions follow a log-normal distribution as illustrated by the overlays on the histograms.

Additionally, the effect of reaction time on the formation of $\mathrm{Sm}_{\mathrm{x}} \mathrm{Ce}_{1-\mathrm{x}} \mathrm{O}_{2-\delta}$ nanoparticles generated with an initial Ce:Sm ratio of $2: 1$ at $750^{\circ} \mathrm{C}$ was investigated for 5,10 , and $20 \mathrm{~min}$, respectively. SEM images of the final products are shown in Fig. 5a-c. After analyzing $>200$ nanoparticles, it is evident that longer reaction times increases the average final nanoparticle size, shown visually in Fig. $5 \mathrm{~d}$-f. With all other conditions kept constant, there should be identical nucleation events and the particle size distribution should be identical upon reaching the final dwell temperature. However, if the longer the reaction proceeds at the final reaction temperature, more growth will occur, particularly in the form of Ostwald ripening [47]. According to the Gibbs-Thompson description of nucleation, dissolution can occur as the reaction proceeds due to the curvature radius of formed particles. These smaller particles can then be re-dissolved into solution and incorporated into larger particles [48].

\subsection{Decomposition mechanism of $\mathrm{Sm}_{\mathrm{x}} \mathrm{Ce}_{1-\mathrm{x}} \mathrm{O}_{2-\delta}$ precursors}

In solid-state reactions, the mechanism by which precursors breakdown plays a major role in the final morphology and properties of the resulting product. To help
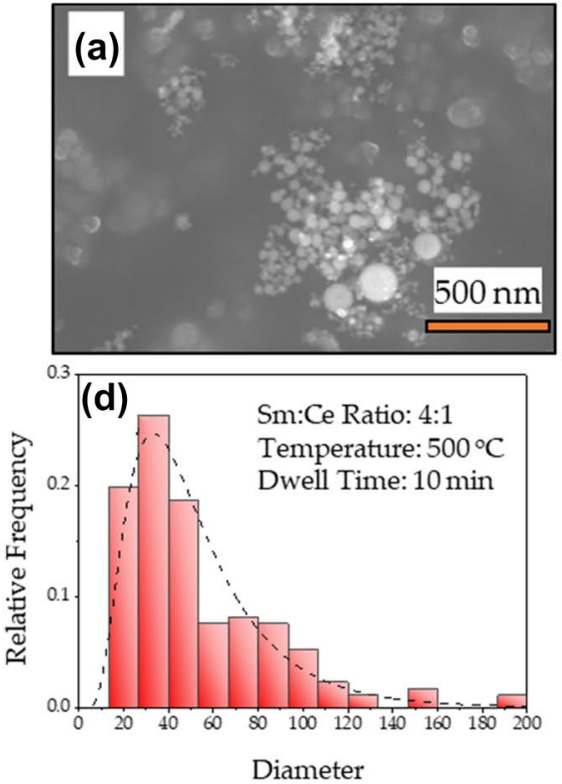
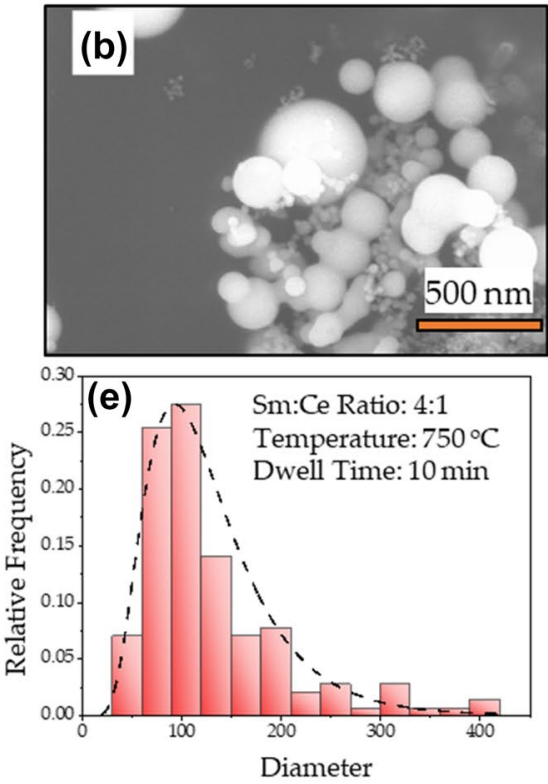
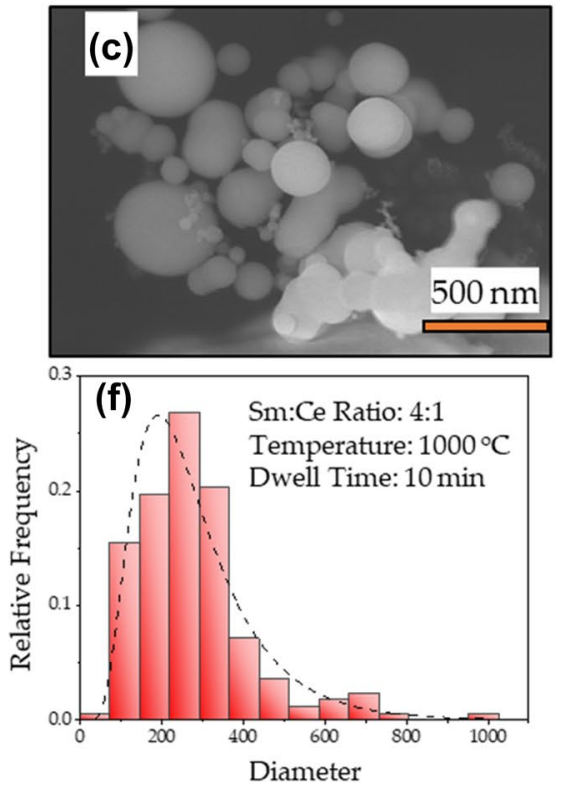

Fig. $4 \mathrm{SEM}$ images of $\mathrm{Sm}_{\mathrm{x}} \mathrm{Ce}_{1-\mathrm{x}} \mathrm{O}_{2-\delta}$ nanoparticles synthesized with a starting Ce:Sm ratio of 4:1, a reaction time of 10 min, at a temperature of $\mathbf{a} 500^{\circ} \mathrm{C} \mathbf{b} 750^{\circ} \mathrm{C}$ and $\mathbf{c} 1000^{\circ} \mathrm{C}$. The corresponding particle size distributions are shown in $\mathbf{d}-\mathbf{f}$ 

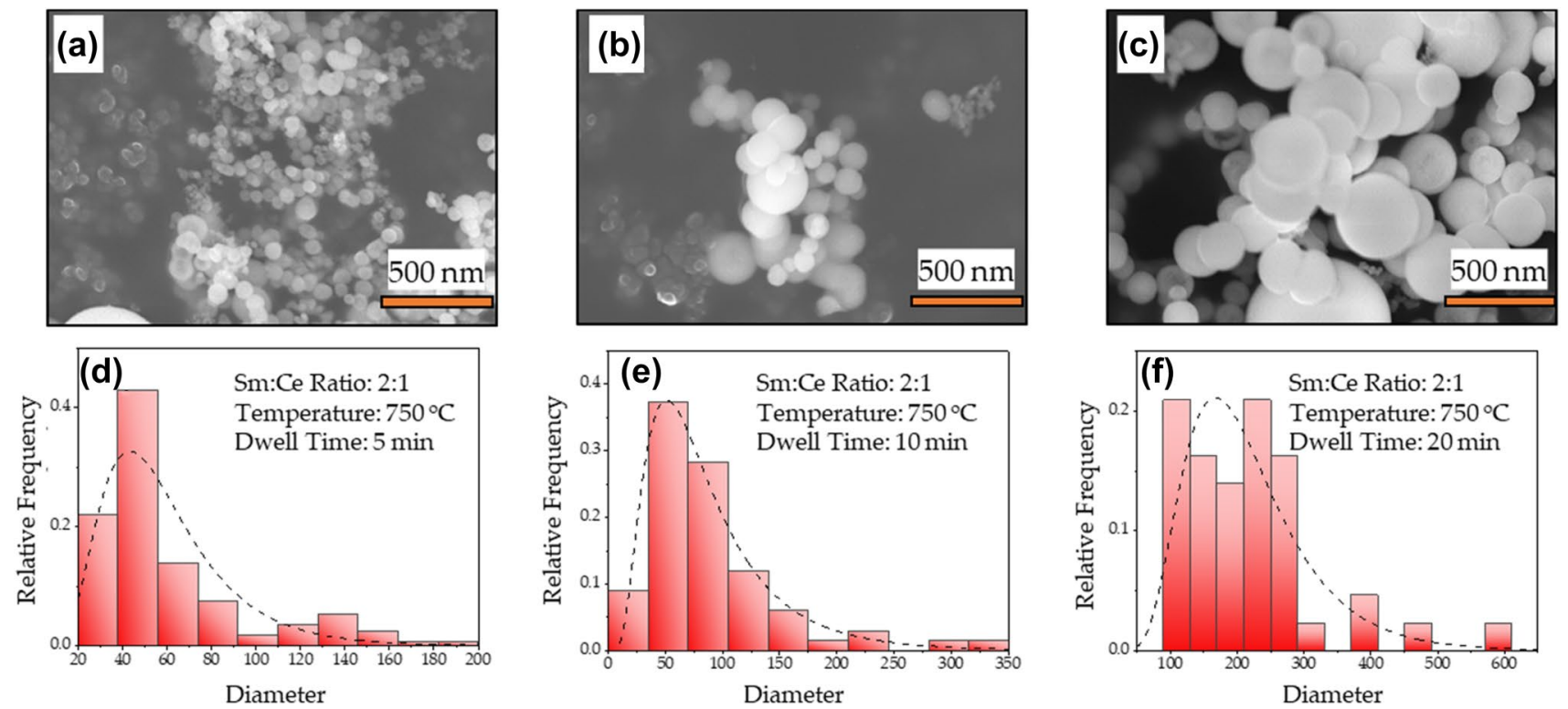

Fig. 5 SEM images of $\mathrm{Sm}_{\mathrm{x}} \mathrm{Ce}_{1-\mathrm{x}} \mathrm{O}_{2-\delta \delta}$ nanoparticles synthesized with a starting Ce:Sm ratio of 2:1, a reaction temperature of $750{ }^{\circ} \mathrm{C}$, and a reaction time of $\mathbf{a} 5 \mathrm{~min} \mathbf{b} 10 \mathrm{~min}$ and $\mathbf{c} 15 \mathrm{~min}$. The corresponding particle size distributions are shown in $\mathbf{d}-\mathbf{f}$

understand the effect of different precursors on final nanoparticle morphology, the thermolysis properties of Ln-precursors were studied using TGA, shown in Fig. 6 . The commercial Ln-acetate/nitrate precursors display multi-step decomposition steps as reported in literature and displayed in Table S2 [49-52]; Ln-TMSA precursors display a single step decomposition. Additionally, Ln-TMSA exhibits a much lower decomposition temperature; $\mathrm{Sm}$ TMSA decomposes at $\sim 200^{\circ} \mathrm{C}$, but Sm-acetate and Smnitrate do not decompose fully until $>400^{\circ} \mathrm{C}$. The simpler decomposition mechanism and lower decomposition temperature of Ln-TMSA are indicators for classical nucleation behavior that can ultimately lead to well defined spherical nanoparticles.
To help identify particle nucleation mechanisms, DFT calculations can provide insight into the breakdown mechanism of $\mathrm{Ln}$-precursors. The presence of a single step decomposition in Ln-TMSA precursors suggests that TMSA ligands are removed from the $\mathrm{Ce} / \mathrm{Sm}$ center without the formation of intermediate states. To evaluate the effect of TMSA ligand removal, a potential energy scan (PES) scan was performed on Ce-TMSA by iteratively stretching the $\mathrm{Ce}-\mathrm{N}$ bond in $0.05 \AA$ steps and allowing the structure to completely relax. The PES shown in Fig. 7, does not indicate the formation of significant intermediate states as indicated by the Lorentz potential like behavior. The small change in slope at $\sim 3.6 \AA$ is a result of the methyl groups loosely interacting with the Ce center but is not a strong
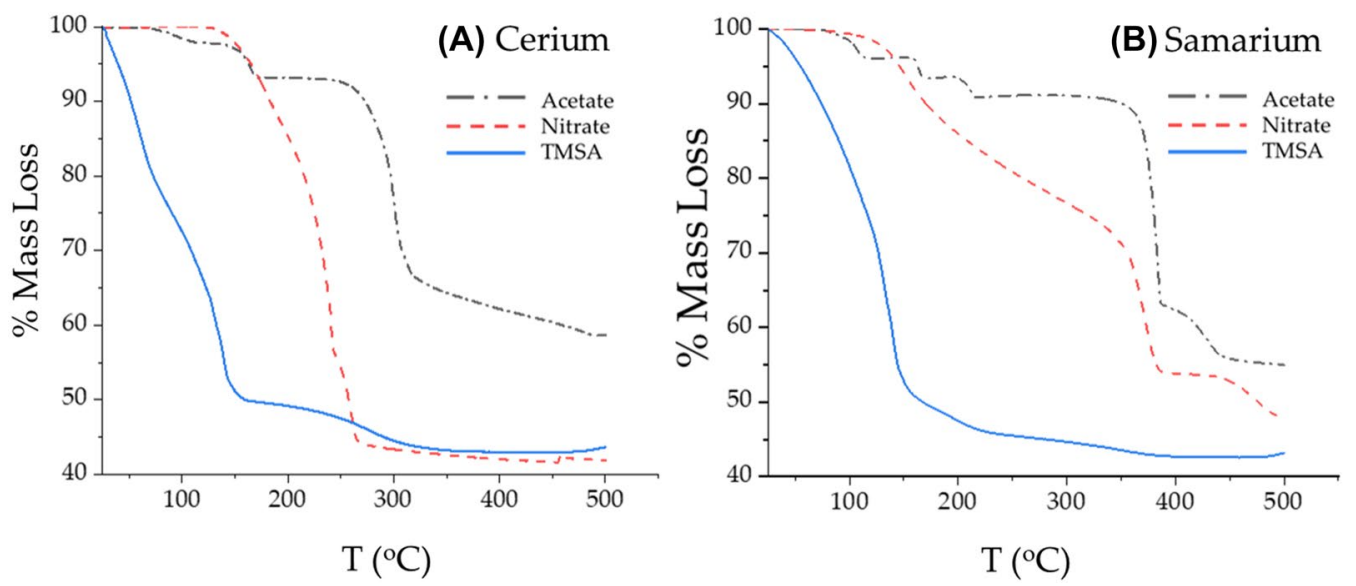

Fig. 6 TGA analysis of $\mathbf{a}$ cerium-based precursors and $\mathbf{b}$ samarium-based precursors 
Fig. 7 PES scan of Ce-TMSA molecule. Insets are snapshots of Ce-TMSA molecule with Ce-N distances of $2.30 \AA$ and $4.95 \AA ̊$. Atom colors: Ce (pink), Si (yellow), C (grey), N (blue), and $\mathrm{H}$ (white)

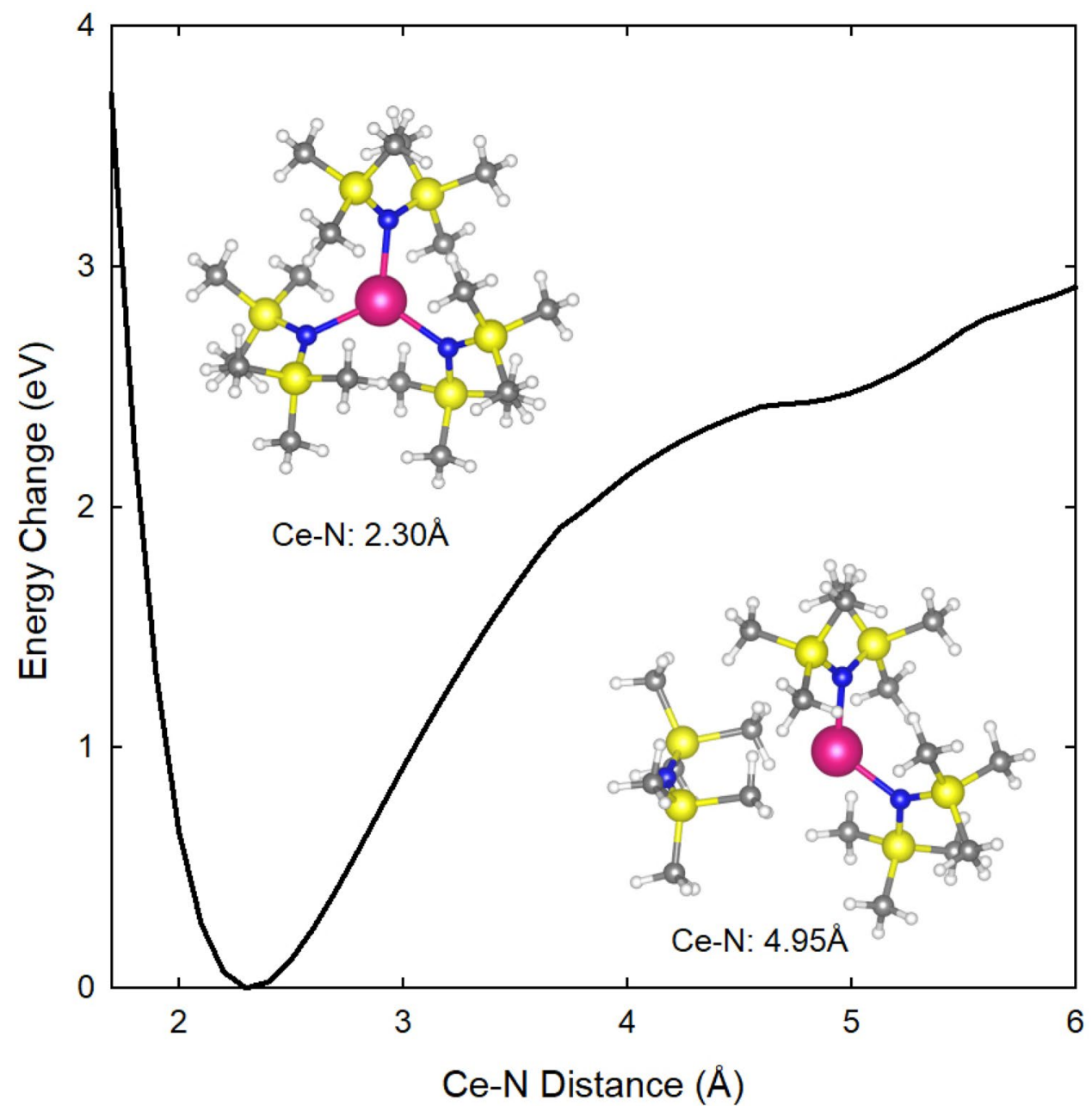

enough interaction to suggest the existence of an intermediate structure.

The effect of intermediate structures can be observed quantitatively by calculating the $E_{D}$ of the first decomposition step for Ln precursors. Shown in Table 2 are the pathways and $E_{D}$ for the first decomposition step of LnTMSA and Ln-acetate precursors calculated as the difference between the relaxed energies of the products and reactants shown schematically in Fig. 8. For the cerium precursors, Ce-TMSA displays a lower binding energy of -4.348 eV as compared to -1.574 for Ce-acetate. Similarly, Sm-TMSA displays a lower binding energy of -3.334 as compared to -1.598 for Sm-acetate. The intermediate structures formed during acetate decomposition result in higher binding energies that make it difficult for molecular species to become available for particle nucleation. Nitrate decomposition also displays a multi-step profile; nitrates are known in molten salt chemistry to break down into nitrite ions before complete decomposition. Due to this behavior, it is expected that the binding energies would be in a similar range as that of the Ln-acetate precursors.
Table 2 Calculated dissociation energies (ED) for the first decomposition step of Ln-acetate and Ln-TMSA precursors

\begin{tabular}{llll}
\hline Precursor & Decomposition Step & \multicolumn{2}{l}{$\begin{array}{l}\text { Dissociation } \\
\text { Energy (eV) }\end{array}$} \\
\cline { 3 - 4 } & & $\mathrm{Ce}$ & $\mathrm{Sm}$ \\
\hline Ln-Acetate & $\begin{array}{c}2 \mathrm{Ln}\left(\mathrm{CH}_{3} \mathrm{CO}_{2}\right)_{3} \rightarrow \mathrm{Ln}_{2} \mathrm{O}\left(\mathrm{CH}_{3} \mathrm{CO}_{2}\right)_{4} \\
+\left(\mathrm{CH}_{3}\right)_{2} \mathrm{CO}+\mathrm{CO}_{2}\end{array}$ & -1.574 & -1.598 \\
Ln-TMSA & $\operatorname{Ln}\left(\mathrm{TMSA}_{3} \rightarrow \operatorname{Ln}(\mathrm{TMSA})_{2}+\mathrm{TMSA}\right.$ & -4.348 & -3.334 \\
\hline
\end{tabular}

According to the TGA data and relevant calculations, it is apparent that the single step decomposition of LnTMSA and subsequent formation of spherical nanoparticles falls in line with LaMer's classical nucleation theory, shown schematically in Fig. 9. In step 1, the concentration of Ln monomers increases at a steady rate as TMSA ligands begin to separate from the metal center. In step 2, the saturation of monomers overcomes the energy barrier at some critical solute concentration $\left(C_{\min }^{\text {nu }}\right)$ to achieve a burst nucleation event. In step 3, crystallization occurs as 


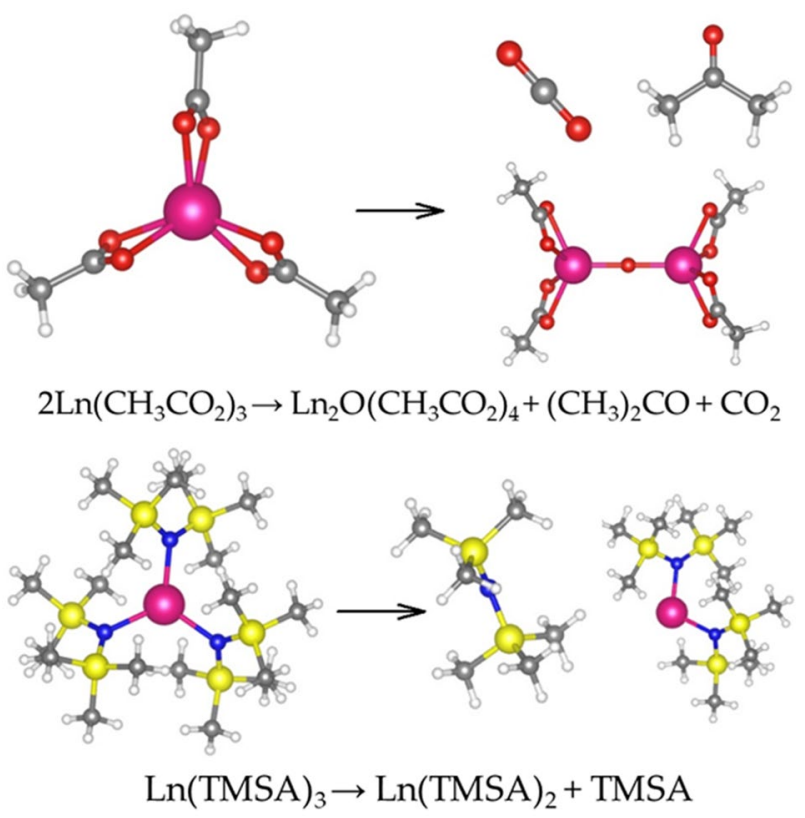

Fig. 8 Schematic of the first step of decomposition for Ln-acetate and Ln-TMSA precursors. Atom colors: Ln (pink), C (grey), H (white), Si (yellow), N (blue)

the concentration of monomers decreases due to continued growth of stable nuclei. In step 4, nuclei continue to grow due to continued monomer diffusion and Ostwald ripening. Spherical nanoparticles are formed due to rapid nucleation followed by the diffusion of readily available monomer species leaving no time for faceted surfaces to form around nuclei. In the case of nitrate and acetatebased precursors, the multi-step decomposition profiles are indicative of a sol-gel polymerization nucleation mechanism that leads to irregular morphologies as facets form semi-randomly on nuclei surfaces [48].

\section{Conclusions}

In conclusion $\mathrm{Sm}_{\mathrm{x}} \mathrm{Ce}_{1-\mathrm{x}} \mathrm{O}_{2-\delta}$ nanoparticles were produced using a microwave-assisted solid-state synthesis. By varying reaction conditions like the molar ratio of reactants, the reaction temperature, and reaction time, spherical nanoparticles with sizes ranging from $20 \mathrm{~nm}$ up to $600 \mathrm{~nm}$ were produced. Based on TGA analysis and DFT calculations, $\mathrm{Sm}_{\mathrm{x}} \mathrm{Ce}_{1-\mathrm{x}} \mathrm{O}_{2-\delta}$ nanoparticles produced with TMSA based precursors grow according to classical LaMer nucleation theory leading to the formation of spherical nanoparticles. The results of this research indicate that microwave-assisted solid-state synthesis can be used to make doped Ceria nanoparticles, but more research is needed in order to control the homogeneity of these particles. Solid state synthesis can be readily scaled up, easily controlled, and does not need solvent or washing, making it an attractive option for producing rare earth oxide-based materials. Future studies will focus on the optimization of $\mathrm{Sm}_{\mathrm{x}} \mathrm{Ce}_{1-\mathrm{x}} \mathrm{O}_{2-\delta}$ nanoparticles as well as the introduction of additional rare earths.
Fig. 9 Schematic for $\mathrm{Sm}_{\mathrm{x}} \mathrm{Ce}_{1-\mathrm{x}} \mathrm{O}_{2-\delta}$ spherical nanoparticle formation based on LaMer nucleation theory

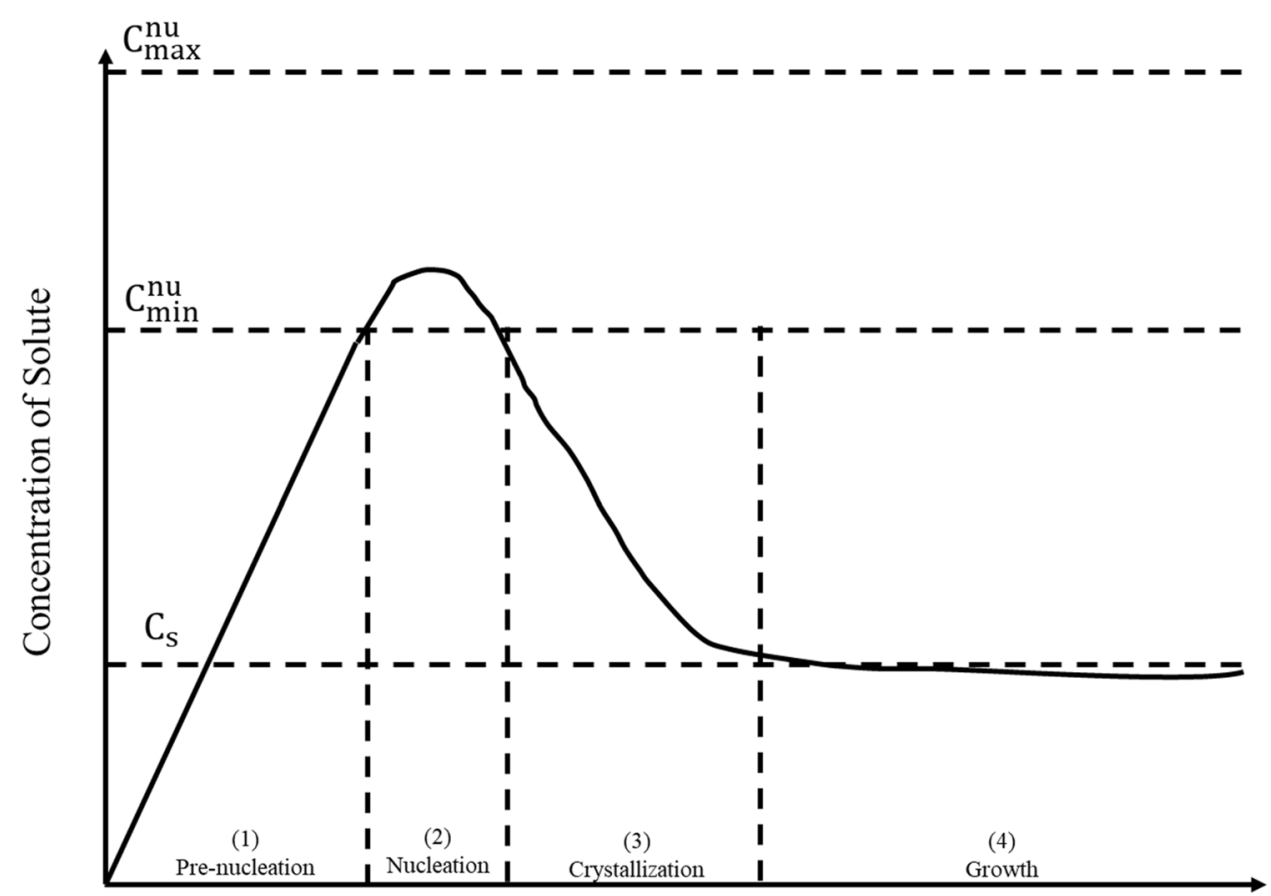

Time 
Authors Contributions The manuscript was written through contributions of all authors. All authors have given approval to the final version of the manuscript.

Funding Sandia National Laboratories is a multimission laboratory managed and operated by National Technology and Engineering Solutions of Sandia, LLC., a wholly owned subsidiary of Honeywell International, Inc., for the U.S. Department of Energy's National Nuclear Security Administration under contract DE-NA0003525. SAND2020-7474 C.

\section{Compliance with ethical standards}

Conflict of interest The authors declare no competing financial interest.

Open Access This article is licensed under a Creative Commons Attribution 4.0 International License, which permits use, sharing, adaptation, distribution and reproduction in any medium or format, as long as you give appropriate credit to the original author(s) and the source, provide a link to the Creative Commons licence, and indicate if changes were made. The images or other third party material in this article are included in the article's Creative Commons licence, unless indicated otherwise in a credit line to the material. If material is not included in the article's Creative Commons licence and your intended use is not permitted by statutory regulation or exceeds the permitted use, you will need to obtain permission directly from the copyright holder. To view a copy of this licence, visit http://creativecommons. org/licenses/by/4.0/.

\section{References}

1. Stefanik TS, Tuller HL (2001) Ceria-based gas sensors. J Eur Ceram Soc 21:1967-1970. https://doi.org/10.1016/S0955 -2219(01)00152-2

2. Subbiah DK, Kulandaisamy AJ, George RB et al (2018) Nano ceria as xylene sensor - Role of cerium precursor. J Alloys Compd 753:771-780. https://doi.org/10.1016/j.jallcom.2018.04.248

3. Álvarez-Asencio R, Corkery RW, Ahniyaz A (2020) Solventless synthesis of cerium oxide nanoparticles and their application in UV protective clear coatings. RSC Adv 10:14818-14825. https ://doi.org/10.1039/d0ra01710h

4. Vangelista S, Piagge R, Ek S et al (2017) Atomic Layer Deposition of Cerium Dioxide Film on TiN and Si Substrates: Structural and Chemical Properties. MRS Adv 2:3005-3010. https://doi. org/10.1557/adv.2017.404

5. Chiu F-C, Lai C-M (2010) Optical and electrical characterizations of cerium oxide thin films. J Phys D Appl Phys 43:075104. https ://doi.org/10.1088/0022-3727/43/7/075104

6. Omar S, Nino JC (2013) Consistency in the chemical expansion of fluorites: A thermal revision of the doped ceria. Acta Mater 61:5406-5413. https://doi.org/10.1016/j.actamat.2013.05.029

7. Bondioli F, Ferrari AM, Lusvarghi L et al (2005) Synthesis and characterization of praseodymium-doped ceria powders by a microwave-assisted hydrothermal (MH) route. J Mater Chem 15:1061-1066. https://doi.org/10.1039/b415628e

8. Kumar A, Babu S, Karakoti AS et al (2009) Luminescence properties of europium-doped cerium oxide nanoparticles: Role of vacancy and oxidation states. Langmuir 25:10998-11007. https ://doi.org/10.1021/la901298q

9. Kumar SA, Kuppusami P, Yen-Pei F (2020) Structural, morphological and electrical properties of Sm-Gd Co-doped ceria thin films for micro-solid oxide fuel cells. Mater Lett 275:128110. https:// doi.org/10.1016/j.matlet.2020.128110

10. Esther Jeyanthi C, Siddheswaran R, Kumar P et al (2014) Structural and spectroscopic studies of rare earths doped ceria (RE La, Sc, Yb:CeO2) nanopowders. Ceram Int 40:8599-8605. https ://doi.org/10.1016/j.ceramint.2014.01.076

11. Esther Jeyanthi C, Siddheswaran R, Medlín R et al (2014) Electrochemical and structural analysis of the $\mathrm{RE} 3+: \mathrm{CeO}_{2}$ nanopowders from combustion synthesis. J Alloys Compd 614:118-125. https ://doi.org/10.1016/j.jallcom.2014.05.208

12. Kosinski MR, Baker RT (2011) Preparation and property-performance relationships in samarium-doped ceria nanopowders for solid oxide fuel cell electrolytes. J Power Sources 196:24982512. https://doi.org/10.1016/j.jpowsour.2010.11.041

13. Huang W, Shuk P, Greenblatt M (1997) Hydrothermal Synthesis and Properties of $\mathrm{Ce} 1-\mathrm{xSm} \times \mathrm{O} 2-\mathrm{x} / 2$ and $\mathrm{Ce} 1-\mathrm{xCaxO}-\mathrm{x}$ Solid Solutions. Chem Mater 9:2240-2245. https://doi.org/10.1021/ $\mathrm{cm} 970425 \mathrm{t}$

14. Trovarelli A, Llorca J (2017) Ceria Catalysts at Nanoscale: How Do Crystal Shapes Shape Catalysis? ACS Catal 7:4716-4735. https:// doi.org/10.1021/acscatal.7b01246

15. Zhou F, Zhao X, Xu H, Yuan C (2007) CeO2 spherical crystallites: Synthesis, formation mechanism, size control, and electrochemical property study. J Phys Chem C 111:1651-1657. https://doi. org/10.1021/jp0660435

16. Mai HX, Sun LD, Zhang YW et al (2005) Shape-selective synthesis and oxygen storage behavior of ceria nanopolyhedra, nanorods, and nanocubes. J Phys Chem B 109:24380-24385. https://doi. org/10.1021/jp055584b

17. Ma Y, Wang X, Li S et al (2010) Samarium-doped ceria nanowires: Novel synthesis and application in low-temperature solid oxide fuel cells. Adv Mater 22:1640-1644. https://doi.org/10.1002/ adma.200903402

18. Hajizadeh-Oghaz M, Razavi RS, Ghasemi A (2016) The Effect of Solution pH Value on the Morphology of Ceria-Yttria Co Stabilized Zirconia Particles Prepared Using the Polymerizable Complex Method. J Clust Sci 27:469-483. https://doi.org/10.1007/ s10876-015-0942-2

19. Barkam S, Ortiz J, Saraf $S$ et al (2017) Modulating the Catalytic Activity of Cerium Oxide Nanoparticles with the Anion of the Precursor Salt. J Phys Chem C 121:20039-20050. https://doi. org/10.1021/acs.jpcc.7b05725

20. Chowdhury S, Lin KS (2011) Synthesis and characterization of 1D ceria nanomaterials for $\mathrm{CO}$ oxidation and steam reforming of methanol. J Nanomater. https://doi.org/10.1155/2011/15769 0

21. Wang D, Kang Y, Doan-Nguyen V et al (2011) Synthesis and oxygen storage capacity of two-dimensional ceria nanocrystals. Angew Chemie Int Ed 50:4378-4381. https://doi.org/10.1002/ anie.201101043

22. Muñoz FF, Acuña LM, Albornoz CA et al (2015) Redox properties of nanostructured lanthanide-doped ceria spheres prepared by microwave assisted hydrothermal homogeneous co-precipitation. Nanoscale 7:271-281. https://doi.org/10.1039/c4nr05630b

23. Amarsingh Bhabu K, Theerthagiri J, Madhavan J et al (2016) Cubic fluorite phase of samarium doped cerium oxide (CeO2)0.96Sm0.04 for solid oxide fuel cell electrolyte. J Mater Sci Mater Electron 27:1566-1573. https://doi.org/10.1007/s1085 4-015-3925-z

24. Shehata N, Samir E, Gaballah S (2016) New optical sensor for peroxides using neodymium-doped-ceria nanoparticles via fluorescence-quenching technique. Sens Actuators B Chem 231:341-348. https://doi.org/10.1016/j.snb.2016.03.036

25. Liu J, Ye J, Liu P et al (2011) Synthesis of monodisperse samarium-doped ceria nanocrystals via a microemulsion-mediated hydrothermal method with secondary light irradiation 
treatment. Mater Lett 65:143-145. https://doi.org/10.1016/j. matlet.2010.10.013

26. Ealias AM, Saravanakumar MP (2017) A review on the classification, characterisation, synthesis of nanoparticles and their application. IOP Conf Ser Mater Sci Eng. https://doi. org/10.1088/1757-899X/263/3/032019

27. Gawande MB, Shelke SN, Zboril R, Varma RS (2014) Microwaveassisted chemistry: synthetic applications for rapid assembly of nanomaterials and organics. Acc Chem Res 47:1338-1348. https ://doi.org/10.1021/ar400309b

28. Donald B, Ghotra JS, Road ME, et al (1973) Low co-ordination numbers in lanthanide and actinide compounds. Part I. The preparation and characterization of tris\{bis(trimethylsilyl)amido\}lanthanides. J Chem Soc Dalt Trans pp 1021-1023

29. M. J. Frisch, G. W. Trucks, H. B. Schlegel, G. E. Scuseria, M. A. Robb, J. R. Cheeseman, G. Scalmani, V. Barone, G. A. Petersson, H. Nakatsuji, X. Li, M. Caricato, A. Marenich, J. Bloino, B. G. Janesko, R. Gomperts, B. Mennucci, H. P. Hratchian, J. V. Ort and DJF (2016) Gaussian 09, Revision A. 02

30. Lee C, Yang W, Parr RG (1988) Development of the Colle-Salvetti correlation-energy formula into a functional of the electron density. Phys Rev B 37:785-789. https://doi.org/10.1103/PhysR evB.37.785

31. Becke AD (1993) Density-functional thermochemistry. III. The role of exact exchange. J Chem Phys 98:5648-5652. https://doi. org/10.1063/1.464913

32. Francl MM, Pietro WJ, Hehre WJ et al (1982) Self-consistent molecular orbital methods. XXIII. A polarization-type basis set for second-row elements. J Chem Phys 77:3654-3665. https:// doi.org/10.1063/1.444267

33. Dolg $M$, Stoll $H$, Preuss $H$ (1989) Energy-adjusted ab initio pseudopotentials for the rare earth elements. J Chem Phys 90:17301734. https://doi.org/10.1063/1.456066

34. Hariharan PC, Pople JA (1973) The influence of polarization functions on molecular orbital hydrogenation energies. Theor Chim Acta 28:213-222. https://doi.org/10.1007/BF00533485

35. Hehre WJ, Ditchfield K, Pople JA (1972) Self-consistent molecular orbital methods. XII. Further extensions of gaussian-type basis sets for use in molecular orbital studies of organic molecules. J Chem Phys 56:2257-2261. https://doi.org/10.1063/1.1677527

36. Petersson GA, Bennett A, Tensfeldt TG et al (1988) A complete basis set model chemistry. I. The total energies of closed-shell atoms and hydrides of the first-row elements. J Chem Phys 89:2193-2218. https://doi.org/10.1063/1.455064

37. Ramezanzadeh B, Bahlakeh G, Ramezanzadeh M (2018) Polyaniline-cerium oxide (PAni-CeO2) coated graphene oxide for enhancement of epoxy coating corrosion protection performance on mild steel. Corros Sci 137:111-126. https://doi. org/10.1016/j.corsci.2018.03.038

38. Xie H, Wang J, Qin Z et al (2014) Octacoordinate metal carbonyls of lanthanum and cerium: experimental observation and theoretical calculation. J Phys Chem A 118:9380-9385. https://doi. org/10.1021/jp504079k

39. Gnanam S, Rajendran V (2013) Influence of various surfactants on size, morphology, and optical properties of $\mathrm{CeO}_{2}$ nanostructures via facile hydrothermal route. J Nanoparticles 2013:1-6. https://doi.org/10.1155/2013/839391

40. Suresh R, Ponnuswamy V, Mariappan R (2013) Effect of annealing temperature on the microstructural, optical and electrical properties of $\mathrm{CeO} 2$ nanoparticles by chemical precipitation method. Appl Surf Sci 273:457-464. https://doi.org/10.1016/j. apsusc.2013.02.062

41. Hos JP, McCormick PG (2003) Mechanochemical synthesis and characterisation of nanoparticulate samarium-doped cerium oxide. Scr Mater 48:85-90. https://doi.org/10.1016/S1359 $-6462(02) 00351-2$

42. Weber WH, Hass KC, McBride JR (1993) Raman study of $\mathrm{CeO}_{2}$ : second-order scattering, lattice dynamics, and particle-size effects. Phys Rev B 48:178-185. https://doi.org/10.1103/PhysR evB.48.178

43. Fernández-García M, Martínez-Arias A, Iglesias-Juez A et al (2000) Structural characteristics and redox behavior of $\mathrm{CeO}_{2}-\mathrm{ZrO}_{2} / \mathrm{Al}_{2} \mathrm{O}_{3}$ supports. J Catal 194:385-392. https://doi. org/10.1006/jcat.2000.2931

44. McBride JR, Hass KC, Poindexter BD, Weber WH (1994) Raman and x-ray studies of Ce1-xRExO2-y, where RE=La, Pr, $\mathrm{Nd}, \mathrm{Eu}, \mathrm{Gd}$, and Tb. J Appl Phys 76:2435-2441. https://doi. org/10.1063/1.357593

45. Deng T, Zhang C, Xiao Y et al (2015) One-step synthesis of samarium-doped ceria and its CO catalysis. Bull Mater Sci 38:11491154. https://doi.org/10.1007/s12034-015-0994-9

46. Wang SF, Yeh CT, Wang YR, Wu YC (2013) Characterization of samarium-doped ceria powders prepared by hydrothermal synthesis for use in solid state oxide fuel cells. J Mater Res Technol 2:141-148. https://doi.org/10.1016/j.jmrt.2013.01.004

47. Baronov A, Bufkin K, Shaw DW et al (2015) A simple model of burst nucleation. Phys Chem Chem Phys 17:20846-20852. https ://doi.org/10.1039/c5cp01745a

48. Varanda LC, Souza CGS, Moraes DA et al (2019) Size and shapecontrolled nanomaterials based on modified polyol and thermal decomposition approaches. A brief review. Acad Bras Cienc. https://doi.org/10.1590/0001-3765201920181180

49. Chicago W OF THE RARE OTHER In a recent study involving the dete $\sim$ ination of the solubilitics of some rare earth and other metal nitrates in organic solvents $1 \mathrm{e} 2$, it was found that little was All of the rare earth nitrate hexahydrates decomposed in the same genera. $\mathrm{p} 15$

50. Melnikov P, Arkhangelsky IV, Nascimento VA et al (2014) Thermolysis mechanism of samarium nitrate hexahydrate. J Therm Anal Calorim 118:1537-1541. https://doi.org/10.1007/s1097 3-014-4067-x

51. Arii T, Kishi A, Ogawa M, Sawada Y (2001) Thermal decomposition of cerium(III) acetate hydrate by a three-dimensional thermal analysis. Anal Sci 17:875-880. https://doi.org/10.2116/anals ci. 17.875

52. Patil KC, Chandrashekhar GV, George MV, Rao CNR (1968) Infrared spectra and thermal decompositions of metal acetates and dicarboxylates. Can J Chem 46:257-265. https://doi. org/10.1139/v68-040

Publisher's Note Springer Nature remains neutral with regard to jurisdictional claims in published maps and institutional affiliations. 